\title{
Prevalence and determinant factors of hookworm infection among school age children in Jawe district, NorthWest Ethiopia
}

\author{
Tadesse Hailu, Wondemagegn Mulu, Bayeh Abera
}

Department of Microbiology, Immunology and Parasitology, College of Medicine and Health Science, Bahir Dar University, P. O. Box: 79, Bahir Dar, Ethiopia.

Email: wondem_32@yahoo.com; bayeabera15@gmail.com

\begin{abstract}
Background: Hookworm infection is a common parasitic infection in sub-Saharan Africa. The prevalence of hookworm infection is influenced by different determinant factors. This study aimed to determine the prevalence of hookworm infection and determinant factors among school age children in North West Ethiopia.

Methods: A cross-sectional study was conducted from April 2016 to August 2016. Children were selected by systematic random sampling and Formoleether concentration technique was used to identify hookworm infection. We conducted descriptive and logistic regression analysis for categorical variables. The adjusted odds ratio was calculated at 95\% confidence interval.

Results: Among 333 children, 49 (14.7\%) were infected with hookworm parasites. Eating raw vegetables, not wearing shoes, absence of regular wearing of shoes and hand washing habit, absence of proper utilization of latrines, absence of deworming were significantly associated $(\mathrm{p}<0.05)$ with hookworm infection.

Conclusion: The prevalence of hookworm infection was high among school age children. Walking with bare foot, hand washing habit, and absence of proper latrine utilization are the major determinant factors for the high prevalence of hookworm infection. Therefore, community mobilization and health education should be done to decrease hookworm infection among school age children in Jawe district.
\end{abstract}

DOI: https://dx.doi.org/10.4314/ahs.v19i3.18

Cite as: Hailu T, Mulu W, Abera B. Prevalence and determinant factors of hookworm infection among school age children in Jawe district, NorthWest Ethiopia. Afri Health Sci. 2019;19(3): 2439-2445. https:// dx.doi.org/10.4314/abs.v19i3.18

\section{Introduction}

Hookworm parasite infection is one of the major members of geohelminthic infections which are common in developing countries. ${ }^{1}$ Although control programs are done, hookworm's disease burden remains high, currently, hookworm affects approximately 500 million people ${ }^{2}$,

\section{Correspondence author:}

Tadesse Hailu,

Associate Professor of Medical Parasitology,

Immunology and Parasitology,

College of Medicine and Health Science,

Bahir Dar University, Ethiopia,

P. O. Box: 79,

Phone: +251912332655:

E.mail: tadessehailu89@yahoo.com;

tadesseh@bdu.edu.et with 5.1 billion at risk for acquiring infection worldwide. ${ }^{3}$ and approximately, 198 million infected cases in sub-Saharan region. ${ }^{4}$

Hookworm infection is also the major causes of mortality and morbidity among the intestinal parasites in Ethiopia. ${ }^{5}$ The distribution of hookworm parasite differs from region to region in the country due to several environmental, social and geographical factors. ${ }^{6}$

School based studies in Ethiopia indicated that the prevalence of hookworm is high among school age children. For instance, high prevalence was recorded in Gorgora Northwest Ethiopia ${ }^{7}$, Bahir Dar special Zone ${ }^{8}$, Babile town, Southern Ethiopia ${ }^{9}$ and rural highland of North-Western Ethiopia. ${ }^{10}$

High prevalence of hookworm is mainly related to several determinant factors including poverty, poor living conditions, personal and environmental hygiene, and sanitation $^{11}$, bare foot walking and exposed with soil. ${ }^{12}$

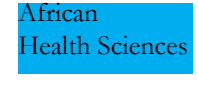

2439
(C) 2019 Hailu et al. Licensee African Health Sciences. This is an Open Access article distributed under the terms of the Creative commons Attribution License (https://creativecommons.org/licenses/BY/4.0), which permits unrestricted use, distribution, and reproduction in any medium, provided the original work is properly cited. 
The disease burden is significantly high in developing countries. Infections by hookworm lead to malnutrition, iron deficiency anaemia, fetal stunted growth and increased vulnerability to other infections ${ }^{13}$ and low educational achievement in school children. ${ }^{14}$

Children are at high risk to being infected by hookworm since they play with soil with their bare hands and walk with bare foot. ${ }^{12}$ This parasite affects the red blood cells (RBCs) in one or another way and causes anemia especially in children. For instance, hookworm consumes RBCs and causes intestinal bleeding which is ideal for blood cell formation and leads to anaemia. ${ }^{15}$ Children having anaemia as well as other parasitic infections are a number of times more likely to be stunted and underweight than those who do not. ${ }^{16}$ Information obtained in health centers indicated that the prevalence of hookworm is the primary helminthic infection among children in Jawe district. However, the available information with respect to hookworm infection and determinant factors in Ethiopia in general and in the study area in particular is lacking. Therefore, this study aimed to determine the magnitude of hookworm infection and determinant factors among school age children NorthWest Ethiopia.

\section{Methods}

\section{Study design, period and area}

A cross-sectional study was conducted from April 2016 to August 2016 among febrile school age children in Jawe Woreda, Awe Zone, Amhara regional state, NorthWest Ethiopia. The altitude of the district is between 648 and 1300 meters. The annual temperature of the study area ranges between $16.68^{\circ} \mathrm{c}$ to $37.6^{\circ} \mathrm{c}$. The average annual rain fall is $1569.4 \mathrm{~mm}$. The study area has an ambient temperature, humidity, vegetation cover, and clay and sand soil types which help the pre-existence of the larva stages of hookworm parasite in the environment.

\section{Sample size determination and sampling}

A total of 333 school age children were included in this study. Simple random sampling technique was conducted until the required sample size is achieved. The samples were collected in Jawe health center and Workmeda health center. The sample size in each health center was allocated by considering the population in the catchment areas. All children age ranging from 6-14 years, attending Jawe health center and Worekmeda health center and who were willing to participate in the study were included in the study. Children under taking antihelminthic drugs during the last 8 weeks from the data collection time were excluded.

\section{Data collection}

Health officers collected data on demographic information, explanatory variables and environmental related factors via face to face interview of parents/guardian of the children.

\section{Stool sample collection}

Freshly passed stool specimens were collected using clean plastic cup at the two health centers.

To detect ova of hookworm in direct microscopy, approximately, $20 \mathrm{mgs}$ of fresh stool sample was put on a slide with wooden applicator, emulsified with a drop of physiological saline $(0.85 \%)$, covered with cover slide and examined under microscope using first $10 \times$ objectives and then $40 \mathrm{x}$ objectives.

In Formole ether concentration techniques (FECT), $0.5 \mathrm{gram}$ of stool sample was transferred in to $10 \mathrm{ml}$ of normal saline in a glass container and mixed thoroughly. Two layers of gauze were placed in a funnel and strained the contents into a $15 \mathrm{ml}$ centrifuge tube. Then $2.5 \mathrm{ml}$ of $10 \%$ formaldehyde and $1 \mathrm{ml}$ of ether was added. The test tubes were mixed well and centrifuged at 1000 revolution for three minutes. The sediment was mixed well, prepared on slide and covered with cover slide and saw the ova of hookworm with microscope.

\section{Quality control}

To ensure reliable data collection, training of laboratory technicians and health officers on data collection and explanation about the study was given before sample collection. Application of standard procedures and accuracy of test results was supervised by principal investigator. The stool cups were labeled based on their serial number. The direct stool microscopy was examined earlier to FECT as soon as the sample arrived. To eliminate observer bias, thick FECT stool slides were examined independently with two experienced laboratory technicians and $10 \%$ of the FECT slides was randomly selected and read by another technician as a quality control. The results of their observation were recorded for later comparison on separate sheets. 


\section{Data analysis}

Data was entered and analyzed using Statistical package for Social Sciences (SPSS) version 20 statistical software. Overall magnitude of hookworm was calculated using descriptive statistics. Strength of association between hookworm infection and various determinant factors was calculated by univariate analysis. Independent variables with Crude odds ratio $(\mathrm{COR})<0.02$ were run to multivariate analysis. Multivariate logistic regression was computed to avoid the cofounding effect and calculating the adjusted odds ratios (AOR) with 95\% confidence intervals (CI).
The differences were considered to be statistically significant if p-value was $<0.05$.

\section{Result}

\section{Demographic characteristics}

A total of 333 school age children took part in the study; $275(82.6 \%)$ from rural with the response rate of $94.5 \%$. Female participants accounted $51.1 \%$ of the total study participants. The mean age and age range of children were 11 years and 8 years, respectively with standard deviation of 2.7 (Table 1 ).

Table 1: Socio-demographic profile of the study participants, Northwest Ethiopia, 2016

\begin{tabular}{clccc}
\hline Variables & & N & \multicolumn{2}{c}{ Hookworm infection } \\
\cline { 3 - 5 } & & & Positive & Negative \\
\hline \multirow{2}{*}{ Age } & $6-9$ & 97 & $11(11.3)$ & $86(88.7)$ \\
(years) & $10-14$ & 236 & $38(16.1)$ & $198(83.9)$ \\
Sex & Male & 163 & $23(14.1)$ & $140(85.9)$ \\
& Female & 170 & $26(15.3)$ & $144(84.7)$ \\
\multirow{2}{*}{ Religion } & Orthodox & 328 & $49(14.9)$ & $279(85.1)$ \\
& Muslim & 5 & $0(0)$ & $5(100)$ \\
\multirow{2}{*}{ Residence } & Rural & 275 & $48(17.5)$ & $227(82.5)$ \\
& Urban & 58 & $1(1.7)$ & $57(98.3)$ \\
\multirow{2}{*}{ Education } & Illiterate & 86 & $13(15.3)$ & $73(84.7)$ \\
& Primary (1-4) & 166 & $25(15.1)$ & $141(84.9)$ \\
& Junior (5-8) & 76 & $10(13.2)$ & $66(86.8)$ \\
& Secondary & 5 & $1(20)$ & $4(80)$ \\
\hline \multirow{2}{*}{ Total } & & 333 & $49(14.7)$ & $284(85.3)$ \\
\hline
\end{tabular}

\section{Hookworm infection}

The overall proportion of hookworm infection among children was $49(14.7 \%)$. The prevalence of hookworm among 6-9 years old and 10-14years old children were $11.3 \%$ and $16.1 \%$, respectively. The prevalence of hookworm infection among able to read and illiterate children were $36(10.8 \%)$ and $13(3.9 \%)$, respectively (Table 1).

\section{Bivariate analysis on hookworm infection}

Determinant factors including eating raw vegetables, having formed stool, walking with bare foot, habit of shoe wear, poor hand wash habit, improper latrine utilization, and absence of deworming were associated with hook worm infection (Table 2). 
Table 2: Bivariate association of considered variables with hookworm infections among school age children in Northwest Ethiopia, 2016

\begin{tabular}{|c|c|c|c|c|c|c|}
\hline \multirow[b]{2}{*}{ Variables } & & \multicolumn{3}{|c|}{ Hook worm infection } & \multirow[b]{2}{*}{ AOR $(95 \% \mathrm{Cl})$} & \multirow{2}{*}{$\begin{array}{r}\text { P. } \\
\text { value }\end{array}$} \\
\hline & & Total & $\begin{array}{c}\text { Infected } \\
{[\mathrm{N}, \%]}\end{array}$ & $\begin{array}{c}\text { Non infected } \\
{[\mathrm{N}, \%]}\end{array}$ & & \\
\hline Eating raw Vegetable & $\begin{array}{l}\text { Yes } \\
\text { No }\end{array}$ & $\begin{array}{l}183 \\
150\end{array}$ & $\begin{array}{c}41(22.4) \\
8(5.3)\end{array}$ & $\begin{array}{l}142(77.6) \\
142(94.7)\end{array}$ & $\begin{array}{c}.21(.06-.70) \\
1\end{array}$ & .01 \\
\hline Wear shoe & $\begin{array}{l}\text { No } \\
\text { Yes }\end{array}$ & $\begin{array}{l}52 \\
281\end{array}$ & $\begin{array}{l}33(63.5) \\
16(5.7)\end{array}$ & $\begin{array}{l}19(36.5) \\
265(94.3)\end{array}$ & $\begin{array}{c}21.14(7.04-63.52) \\
1\end{array}$ & .00 \\
\hline How often wear shoe? & $\begin{array}{c}\text { Sometimes } \\
\text { Always }\end{array}$ & $\begin{array}{l}199 \\
134\end{array}$ & $\begin{array}{c}41(20.6) \\
8(6.0)\end{array}$ & $\begin{array}{l}158(79.4) \\
126(94)\end{array}$ & $\begin{array}{c}0.30(.09-.69) \\
1\end{array}$ & .04 \\
\hline Latrine utilization & $\begin{array}{c}\text { Sometimes } \\
\text { Always }\end{array}$ & $\begin{array}{l}191 \\
142\end{array}$ & $\begin{array}{c}7(3.7) \\
42(29.6)\end{array}$ & $\begin{array}{l}184(96.3) \\
100(70.4)\end{array}$ & $\begin{array}{c}0.20(.06-.64) \\
1\end{array}$ & .01 \\
\hline Hand washing habit & $\begin{array}{c}\text { Sometimes } \\
\text { Always }\end{array}$ & $\begin{array}{l}82 \\
251\end{array}$ & $\begin{array}{l}34(41.5) \\
15(6.0)\end{array}$ & $\begin{array}{l}48(58.5) \\
236(94)\end{array}$ & $\begin{array}{c}0.07(.02-19) \\
1\end{array}$ & .000 \\
\hline Deworming & $\begin{array}{l}\text { Yes } \\
\text { No }\end{array}$ & $\begin{array}{l}183 \\
150 \\
\end{array}$ & $\begin{array}{l}15(8.2) \\
34(22.7) \\
\end{array}$ & $\begin{array}{l}168(91.8) \\
116(77.3) \\
\end{array}$ & $\begin{array}{c}1 \\
3.00(1.03-8.3) \\
\end{array}$ & .044 \\
\hline
\end{tabular}

\section{Multivariate analysis on hookworm infection}

The odd of hookworm infection was $79 \%$ lower in school age children who did not eat raw vegetables than children are raw vegetables. Children who washed their hands were $93 \%$ protected than children that didn't wash their hand. Children who did not wear shoes were 21.14 (AOR) times more likely to be infected by hookworms.
The odds of hookworm infection was $80 \%$ lower in children who properly used latrines than in those whodid not. Children who de-wormed were 2.93 (AOR) times more likely to be protected than those who did not get de-wormed. Children with formed stool were 3.45 (AOR) times more likely to give positive result for hookworm infection than those with a semi-solid stool (Table 3). 
Table 3: Multivariate association of considered variables with hookworm infections among school age children in Northwest Ethiopia, 2016

\begin{tabular}{|c|c|c|c|c|c|c|}
\hline \multirow[b]{2}{*}{ Variable } & & \multirow[b]{2}{*}{ Total } & \multicolumn{2}{|c|}{ Hookworm infection } & \multirow[b]{2}{*}{ AOR $[95 \% \mathrm{Cl}]$} & \multirow[b]{2}{*}{$p$-value } \\
\hline & & & $\begin{array}{l}\text { Infected } \\
{[\mathrm{N}, \%]}\end{array}$ & $\begin{array}{l}\text { Non infected } \\
{[\mathrm{N}, \%]}\end{array}$ & & \\
\hline Eating raw & Yes & 183 & $41(22.4)$ & $142(77.6)$ & $0.21(0.06-0.70)$ & \multirow{3}{*}{0.0} \\
\hline \multirow[t]{2}{*}{ Vegetable } & No & 150 & $8(5.3)$ & $142(94.7)$ & 1 & \\
\hline & No & 52 & $33(63.5)$ & $19(36.5)$ & $21.14(7.04-$ & \\
\hline \multirow[t]{2}{*}{ Wear shoe } & Yes & 281 & $16(5.7)$ & $265(94.3)$ & 63.5) & 0.00 \\
\hline & & & & & 1 & \multirow[b]{3}{*}{0.0} \\
\hline How often & Sometimes & 199 & $41(20.6)$ & $158(79.4)$ & $0.30(0.09-0.96)$ & \\
\hline wear shoe? & Always & 134 & $8(6.0)$ & $126(94)$ & & \\
\hline Latrine & Sometimes & 191 & $7(3.7)$ & $184(96.3)$ & $0.20(0.06-0.64)$ & \multirow{2}{*}{0.01} \\
\hline utilization & Always & 142 & $42(29.6)$ & $100(70.4)$ & 1 & \\
\hline Hand & Sometimes & 82 & 34 (41.5) & $48(58.5)$ & $0.07(0.02-0.19)$ & \multirow[b]{2}{*}{0.00} \\
\hline $\begin{array}{l}\text { washing } \\
\text { habit }\end{array}$ & Always & 251 & $15(6.0)$ & $236(94)$ & 1 & \\
\hline \multirow{2}{*}{ Deworming } & No & 150 & $34(22.7)$ & $116(77.3)$ & $2.93(1.03-8.30)$ & \multirow{2}{*}{0.04} \\
\hline & Yes & 183 & $15(8.2)$ & $168(91.8)$ & 1 & \\
\hline
\end{tabular}

\section{Discussion}

Hookworm infection is a public health problem and is more severe in resource poor countries. Poor hygiene, open defecation, habit of walking with bare foot and scarcity of pure water are major determinants for the high prevalence. ${ }^{17}$

The prevalence of hookworm infections (14.7\%) in the present study was higher than a study done in Kuma$\mathrm{si}^{18}$, comparable with previous study conducted in Jim$\mathrm{ma}^{19}$, and South Gondar ${ }^{20}$ but lower than a study done in SouthWestern Tanzania ${ }^{21}$, Haryana state of India ${ }^{22}$, and NorthWest Ethiopia ${ }^{10}$. This might be due to difference in socioeconomic status, health information, waste disposal system, sample collection season, soil type, as well as climatic and topographic factors of the study areas.

Most of the time, hookworm transmission is through skin penetration, but some times hookworm parasites may be transmitted to human being by ingestion of filariform larvae of Ancylostoma duodenale in contaminated food. ${ }^{23}$ In the present study we found that children who did not eat raw vegetables were less likely to be infected by hookworm parasites. Similar result was identified in Sudan. ${ }^{24}$ In this study the prevalence of hookworm infection among children who didn't wear shoes was significantly higher than those who wore shoes. Likewise, similar findings were reported in South Gondar ${ }^{20}$, and Awassa. ${ }^{25}$

Contaminated hands with filariform larvae can transmit hookworm infection during eating food. ${ }^{23}$ Unclean hand, untrimmed nails, contamination of water, poor sanitation and defecation in open field greatly favor transmission of worm infection especially in schools resulting in high endemicity of hook worm infection. ${ }^{22}$ Proper utilization of latrines and good hand washing habits are ideal for prevention of intestinal parasitosis. ${ }^{26}$ In the present study, children who were unable to utilize latrines and wash hands properly were susceptible to be infected by hookworm parasite. This finding was similar with previous study conducted in South Ethiopia ${ }^{27}$ and NorthWest Ethiopia ${ }^{28}$ and rural community of Thailand. ${ }^{29}$ 
Depending on the prevalence in endemic area, de-worming should be given for helmenthic infections. Dewormed children in the presence study showed low prevalence of hookworm parasite infection. This result was in agreement with previous studies in Western Uganda. ${ }^{30}$

\section{Conclusion}

The prevalence of hookworm infection was high among school age children. Walking bare foot, hand washing habit, and absence of proper latrine utilization are the major determinant factors for the high prevalence of hookworm infection. Therefore, community mobilization, health education and de-worming should be done to decrease the burden of hookworm infection among school aged children in Jawe district.

\section{Conflict of interest}

All the authors have seen the manuscript and approve it for submission. The authors have no competing interest in the publication of the manuscript to declare

\section{Authors' contribution}

TH, conceived, designed and wrote, did the analysis and revised the manuscript. WM \& BA critically revised the manuscript. All authors read and approved the final manuscript.

\section{Authors' information}

TH is assistant professor of Medical Parasitology at College of Medicine and Health Sciences, Bahir Dar University. WM is assistant professor of Medical Microbiology at college of Medicine and Health sciences, Bahir Dar University. BA is associate professor of Medical Microbiology at College of Medicine and Health Sciences, Bahir Dar University

\section{Acknowledgement}

The authors highly acknowledge the Bahir Dar University, Callege of Medicine and Health Sciences which covered the budget of the project.

\section{References}

1. World Health Organization. Prevention and Control of Intestinal Parasitic Infections, WHO Technical Report Series 741, WHO, Geneva, Switzerland, 1987.

2. Global, regional, and national incidence, prevalence, and years lived with disability for 301 acute and chronic diseases and injuries in 188 countries, 1990-2013: a sys- tematic analysis for the Global Burden of Disease Study 2013, 2015. Lancet 386(9995).743-800.

3. Pullan RL, Brooker SJ., The global limits and population at risk of soil-transmitted helminth infections in 2010. Parasit Vectors, 2012. 5: p.81.

4. Hotez PJ, Kamath A., Neglected Tropical Diseases in Sub-Saharan Africa: Review of Their Prevalence, Distribution, and Disease Burden. PLoS Negl Trop Dis, 2009.3(8): p.e412.

5. Leykun J., Soil Transmitted Helminthic Infection and Schistosoma mansoni in School Children from Chilga District, North West Ethiopia. Ethiop J Health Science, 2001. 11:p.79-87.

6. Legesse M, Erko B.,Prevalence of intestinal parasites among school children in a rural area close to the southeast of Lake Langano, Ethiopia. EthiopJ Health Dev, 2004. 18(2): p. 116-120.

7. Tekeste Z, Belyhun Y, Gebrehiwot A, Moges B, Workineh M, Ayalew G, Mandefro M, Kassu A., Epidemiology of intestinal schistosomiasis and soil transmitted helminthiasis among primary school children in Gorgora, NorthWest Ethiopia. Asian Pac J Trop Dis, 2004. 3(1): p.61-64.

8. Abera B, Alem G, Yimer M, Herrador Z., Epidemiology of soil-transmitted helminths, Schistosoma mansoni, and haematocrit values among school children in Ethiopia. J Infect Dev Ctries, 2013 .7(3):p. 253-260.

9. Tefera E, Mohammed J, Mitiku H., Intestinal helminthic infections among elementary students of Babile town, Eastern Ethiopia. Pan Afr Med J, 2015 . 20: p.50.

10. Amor A, Rodriguez E, Saugar JM, Arroyo A, López-Quintana B, Abera B, Yimer M, Yizengaw E, Zewdie D, Ayehubizu Z, Hailu T, Mulu M, Echazú A, Krolewieki AJ, Aparicio P, Herrador Z, Anegagrie M, Benito A., High prevalence of Strongyloides stercoralis in schoolaged children in a rural highland of north-western Ethiopia: the role of intensive diagnostic work-up. Parasites Vector, 2016 .9:p.617.

11. Ohaeri CC, Orji NB, Intestinal Parasites among Undergraduate Students of Michael Okpara University of Agriculture, Umudike Abia State, Nigeria. World Appl Sci $J, 2013$. 25 (8):p. 1171-1173.

12. Jiraanankul V, Aphijirawat W, Mungthin M, Khositnithikul R, Rangsin R, Traub RJ, Piyaraj P, Naaglor T, Taamasri P, Leelayoova S., Incidence and Risk Factors of Hookworm Infection in a Rural Community of Central Thailand. Am J Trop Med Hyg, 2011 .84(4):p. 594-598.

13. Obiamuiwe BA, Nmorsi., Human gastro-intestinal 
parasites in Bendel State, Nigeria. Nigerian Journal of Parasitol, 1990 .32: p.177-183.

14. Nokes C, Cooper ES, Robinson BA, Budy DAP., Geohelminth infection and academic assessment in Jamaican children. Trans Roy Soc Trop Med Hyg, 1991 .85:p.272-273. 15. Albonico M, Stoltzfus RJ, Savioli L, Tielsch JM, Chwaya HM, Ercole E, Cancrini G. Epidemiologicalevidence for a differential effect of hookworm species, Ancylostoma duodenale or Necator americanus, on iron status of children. Int J pidemiol, 1998.27 (3):p.530-537.

16. Hughes RJ, Sharp DS, Hughes MC; Akau'ola S, Heinsbroek P, Velaydudhan R., Environmental influences on helminthiasis and nutritional status among Pacific schoolchildren. Int Jour Environ Health Res, 2004 .14:p. 163-177.

17. Hossain M, Bhuiyan JU., Hookworm infection: A neglected tropical disease of mankind. Journal of Advanced Veterinary and Animal Research, 2016 . 3(4): p. 297-320.

18. Walana W, Aidoo ENK, Tay SCK., Prevalence of hookworm infection: a retrospective study in Kumasi. Asian Pac J Trop Biomed, 2014 .4(1): p.S158-S161.

19. Debalke S, Worku A, Jahur N, Mekonnen Z., Soil transmitted helminths and associated factors among school children in government and private primary school in jimma town, SouthWest Ethiopia. Ethiop J Health Sci 2013 .23:p. 3.

20. Shiferaw MB, Mengistu AD., Helminthiasis: Hookworm Infection Remains a Public Health Problem in Dera District, South Gondar, Ethiopia. PLoS One, 2015 . 10(12): e0144588.

21. Riess H, Clowes P, Kroidl I, Kowuor DO, Nsojo A, Mangu C, Schule SA, Mansmann U, Geldmacher C, Mhina S, Maboko L, Hoelscher M, Saathoff E.,Hookworm Infection and Environmental Factors in Mbeya Region, Tanzania: A Cross- Sectional, Population-Based Study. PLoS Negl Trop Dis , 2013.7(9): e2408.

22. Verma R, Chawla S, Khanna P, Singh S, Singh A, Dixit P, Saini M, Singh B., Determinants of hookworm infestation among school going children: a cross sectional study. CIB Tech J Microbiol, 2015.4 (2): p.1-5.

23. Brooker S, Jeffrey Bethony J, Hotez PJ. Human Hookworm Infection in the 21st Century. Adv Parasitol, 2004. 58:p.197-288.

24. Mohamed MA, Siddig EE, Elaagip AH, Edris AMM, Nasr AA., Parasitic contamination of fresh vegetables sold at central markets in Khartoum state, Sudan. Ann Clin Microbiol Antimicrob, 2016 .15:p. 17.

25. Erosie L, Merid Y, Ashiko A, Ayine M, Balihu A, MuzeyinS, Teklemariam S, Sorsa S., Prevalence of Hookworm infection and hemoglobin status among rural elementary school children in Southern Ethiopia. Ethiop. J. Health Dev, 2002. 16(1):p.113-115.

26. Vivas A, Gelaye B,Nigusu Aboset N, Kumie A, Berhane Y, Williams MA., Knowledge, Attitudes, and Practices (KAP) of Hygiene among School Children in Angolela, Ethiopia. J Prev Med Hyg. Jun, 2010 .51(2): p.73-79.

27. Ketema H, Biruksew A, Mekonnen Z., Prevalence of Necator americanus infection and risk factors among school-age children in Mirab Abaya District, South Ethiopia. Asian Pac J Trop Dis, 2015 .5(5): p.363-368.

28. Gedefaw M, Amsalu Y, Tarekegn M, Awoke W., Opportunities, and Challenges of Latrine Utilization among Rural Communities of Awabel District, Northwest Ethiopia. Open J Epidemiol, 2015 .5:p. 98-106.

29. Jiraanankul V, Aphijirawat W, Mungthin M, Khositnithikul R, Rangsin R, Traub RJ, Piyaraj P, Naaglor T, Taamasri P, Leelayoova S., Incidence and Risk Factors of Hookworm Infection in a Rural Community of Central Thailand. Am J Trop Med. Hyg, 2011 . 84(4):p. 594-598.

30. Ndyomugyenyi R, Kabatereine N, Olsen A, Magnussen P. Efficacy of ivermectin and albendazole alone and in combination for treatment of soil-transmitted helminths in pregnancy and adverse events: a randomized open label controlled intervention trial in Masindi district, western Uganda. Am J Trop Med Hyg, 2008 .79(6): p.85663. 